Open Access

\title{
Clinical outcomes of allograft with locking compression plates for elderly four-part proximal humerus fractures
}

Hua Chen, Xinran Ji, Qun Zhang, Xiangdang Liang and Peifu Tang ${ }^{*}$

\begin{abstract}
Background: The aim of this study is to explore the clinical outcomes of anatomical allograft or fibula shaft augmentation with locking compression plates (LCPS) in elderly patients with four-part proximal humeral fracture (PHF).

Methods: A total of 22 elderly patients with four-part PHF underwent allograft augmentation with LCPs for treatment. Among them, 7 cases received anatomical allograft and 15 patients received fibula shaft. Constant-Murley score (CMS), the disability of the arm, shoulder and hand (DASH) score, and subjective ratings, radiographic imaging, range of motion $(\mathrm{ROM})$, and complications were recorded as postoperative evaluations.

Results: Although the ROM and strength were considerably limited compared with the normal side, there were no significant differences in pain and daily activity between the unaffected and affected sides at the last follow-up according to the CMS. Additionally, no significant differences were found in the subjective ratings and CMS and DASH scores between the patients augmented with fibular shaft and anatomical allograft. Among the 15 patients who received fibular shaft, one case developed avascular necrosis (AVN) and screw cutout, but satisfactory outcomes were obtained after removal of implant. Besides, varus displacement occurred in one case, the patient acquired good function without revision. There were no infection, bone nonunion, and hardware-related complications occurred in any case.
\end{abstract}

Conclusions: Both anatomical allograft and fibula shaft with LCPs showed relatively good clinical outcomes for elderly patients with four-part PHF.

Keywords: Four-part proximal humeral fracture, Locking compression plates (LCPs), Fibular shaft, Anatomical allograft

\section{Background}

Proximal humeral fractures (PHFs) account for approximately $10 \%$ of all fractures [1], and the incidence is increasing with age [2]. Most PHFs are low-energy osteoporotic injury occurred in the elderly and afflict two or three times as many women as men [3]. This fracture still remains a major challenge for surgeons worldwide [4]. It has been reported that approximately 80 to $90 \%$ of patients with minimally displaced PHF can be managed by nonoperation [5]. Four-part PHF is the most severe type among PHFs according to the Neer

\footnotetext{
*Correspondence: tangpf301@163.com

The Department of Orthopaedic Surgery, The General Hospital of People's Liberation Army (301 Hospital), 28 Fuxing Road, Wukesong, Beijing 100000, China
}

\section{Biomed Central}

classification [6]. Nonoperative treatment for four-part PHF often results in less favorable clinical and anatomical outcomes [7, 8]. Shoulder hemiarthroplasty (HA) is advocated for treatment of this fracture type by prevention of varus collapse, deformity, and avascular necrosis risk $[9,10]$. However, the functions and outcome evaluations are still controversial [11].

Recently, locking compression plate (LCP) demonstrates satisfactory results for severely displaced PHF compared with conventional plate. The fixed-angle construct could improve the fracture stability and increase the resistance to pullout through the bone-plate interface with a single beam construct, especially useful in poor-quality cancellous bone of the proximal humerus. However, some complications, such as avascular necrosis (AVN), screw cutout, implant 
failure, plate impingement, head collapse, and infection, have been reported [12, 13].

Autologous bone grafting might be an alternative method for overcoming varus collapse. However, autologous bone grafting which harvested from the patients themselves has some complications, such as vascular or neurologic injuries, deep infections at the donor site, and deep hematoma formation, while the efficiency of allograft bone grafting with LCP was rarely reported.

In the present study, we evaluated the outcomes of elderly patients with fresh four-part PHF who underwent fibular shaft or anatomical allograft for restoration of medial strut with LCPs.

\section{Materials and methods \\ Participants}

This research was a retrospective study and was approved by the Ethics Committee of General Hospital of People's Liberation Army (301 Hospital). Written informed consents were obtained from all enrolled patients.

Between January 2010 and December 2011, patients who met the following inclusion criteria were recruited: (1) the patients suffered from an acute four-part PHF with or without fracture dislocation and (2) patients' fragments were either displaced more than $1.0 \mathrm{~cm}$ or angulated more than $45^{\circ}$ and were preoperatively conformed by radiograph or computed tomography (CT) with three-dimensional (3D) reconstructions. Patients who had any previous history of shoulder surgery or chronic nonunion, and addiction of cigarettes and/or drugs were excluded. Those who later refused to participate or failed to cooperate with us in this trial were also excluded.

\section{Preparation of allograft for medial support}

There are two kinds of allografts for medial support: fibular allograft and anatomical allograft (Fig. 1). Fibular allograft was obtained from bone bank where it was cut into an appropriate length using a sagittal oscillating saw. Anatomical allograft was obtained from cadaveric donors. It was modified into a specific shape to fulfill the bone void according to the intramedullary geometry of the proximal humerus through computer virtual design with Pro-E software. All the strut allografts were stored at temperatures between $-60{ }^{\circ} \mathrm{C}$ and $-80{ }^{\circ} \mathrm{C}$ until use. It is important to emphasize that some bloodtransmitted diseases in the allografts, e.g., acquired immune deficiency syndrome, hepatitis $B$ and $C$, or syphilis, should be excluded.

\section{Operative technique}

All surgical procedures were conducted by two of our well-experienced authors (Hua Chen and Peifu Tang). The choice for fibular shaft or anatomical allograft was made randomly. Briefly, the patients were placed in a

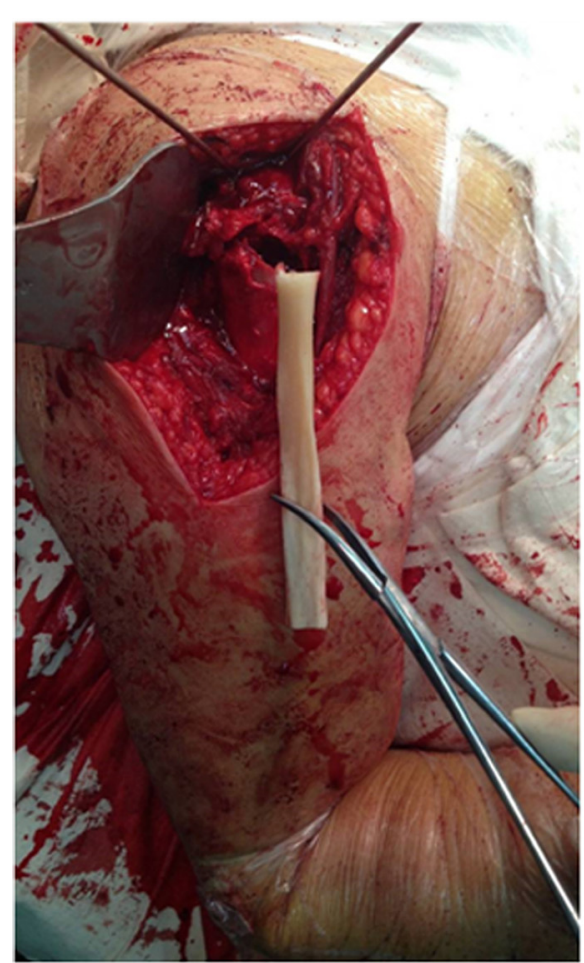

A

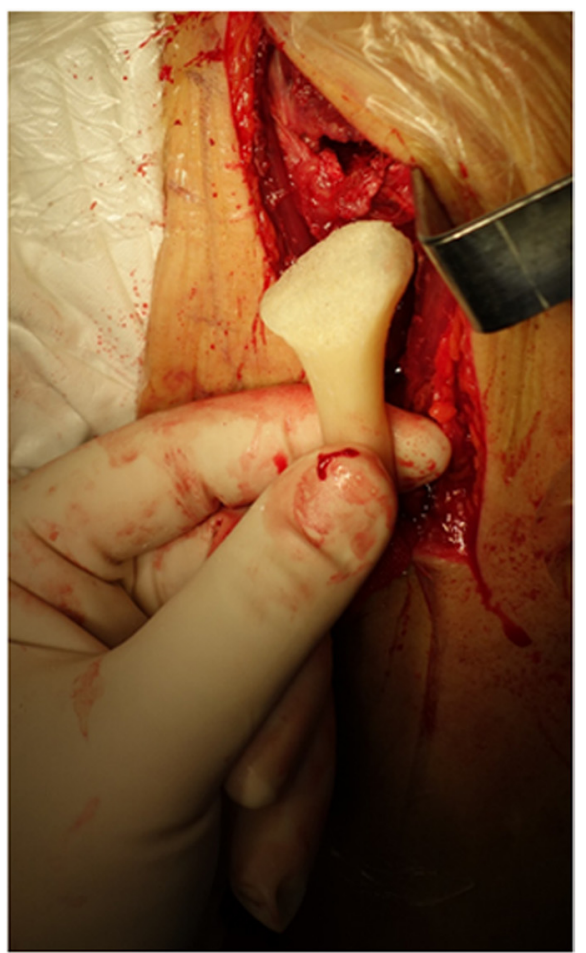

B

Fig. 1 Two kinds of allografts for medial support. a Fibular allograft. b Anatomical allograft 
beach chair position followed by general anesthesia and then received a standardized approach that was described previously [14]. Preoperative skin preparation was applied to the affected hemi-extremity. Approximately a $15-\mathrm{cm}$ skin incision was made. The insertion of the deltoid muscle was one-half detached posteriorly subperiosteally. All patients received $1.5 \mathrm{~g}$ of cefuroxime preoperatively.

After the fracture sites were being exposed thoroughly, the long head of the biceps was identified and the configuration of the fracture was checked. Then, laminar spreader was put into intramedullary canal through lateral cortical window of tuberosity fracture sites with $30^{\circ}$ of retroversion. The elbow was kept anteriorly. The humeral head and shaft were reduced with the help of the laminar spreader under (Fig. 2), especially when the medial calcar continuation and the normal neck shaft angle were restored. To prevent damaging the vascular supply to the humeral head, management of the articular segment was employed extracapsularly. Shaft traction was maintained by a surgical assistant. The intramedullary strut was inserted into the intramedullary canal distal to fracture site and was then driven back to the proximal humeral bone. Intramedullary strut allograft was pushed onto the medial calcar to support the humeral head for prevention of varus displacement and deformity of the humeral head.
After that, the greater tuberosity fragment was reduced and sutured with No. 5 Ethibond sutures to maintain the reduction. The LCPs (Synthes, Switzerland) were placed between 5-10 $\mathrm{mm}$ lateral to the bicipital groove and 15$20 \mathrm{~mm}$ inferior to the vertex of the humerus head. Headlocking screws were placed in the subcortical bone, and the distal screws were placed in the shaft. The location of the screw tip was confirmed by an image intensifier. After careful irrigation, a negative suction drain was placed in the wound followed by layer closure.

\section{Postoperative rehabilitation}

The shoulders were immobilized in a sling postoperatively. Patients received passive mobilization and pendulum exercises immediately. Additionally, physiotherapy was performed to all patients and gradually discontinued about 3 weeks. Both passive- and active-assisted exercises were permitted in a rehabilitation center at the second week after surgery. The forward elevation and abduction was limited to $100^{\circ}$, and external rotation was limited to $30^{\circ}$.

\section{Clinical and radiological evaluation}

The subjective ratings of the outcome include excellent, good, fair, and poor. Functional outcomes were assessed using the disability of the arm, shoulder and hand (DASH)
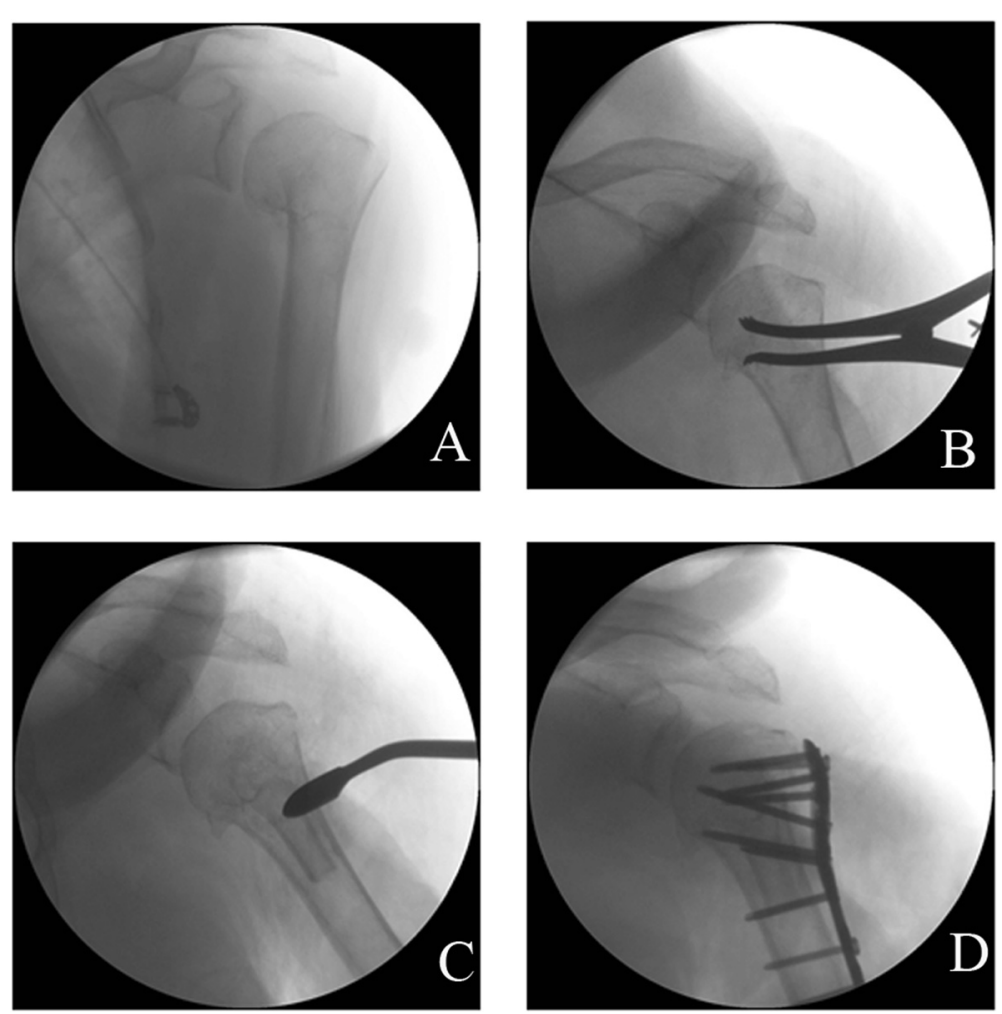

Fig. 2 The humeral head and shaft are reduced with the help of laminar spreader under fluoroscopy and fixed by locking compression plates. a Before reduction. b Reduction with the help of laminar spreader. c Insertion of fibula. d Fixation by steel plate and screw 
score [15] and Constant-Murley score (CMS) [16]. Bone mineral density (BMD) was assessed by dual-emission X-ray absorptiometry (DXA). Radiographs (standard AP position, axillary, and scapular Y views) were reviewed postoperatively. The radiographic follow-up periods were postoperatively 4, 8, and 13 weeks and then again 12, 24, and 48 months following surgery. However, implant should be removed when there were hardware-related symptoms. In addition, complications, such as varus displacement of humeral head, AVN, screw penetration, and infection, were also recorded.

\section{Comparison of functional outcomes}

Functional outcomes such as pain, activity, range of motion, and strength of the fractured side and the normal side of patients between the two surgery groups were evaluated and compared.

\section{Statistical analysis}

Continuous variables, presented as the mean and standard deviation (SD), were compared by the Student $t$ test to detect the group differences. Qualitative data of groups was compared by the $\chi^{2}$ test. Statistical analysis was performed by SAS Statistical Software 9.1.3 (SAS Institute Inc., Cary, NC, USA). $P$ value $<0.05$ was considered as significant difference.

\section{Results}

\section{Patients' characteristics}

Finally, a total of 22 cases consisting of 9 males and 13 females were recruited in our study. The mean age was $67.2 \pm 9.0$ years (range, $52-84$ years). The injury was mostly caused by falling from standing height $(n=17)$. The other six cases were injured from fracture dislocation $(n=4)$ and valgus-impacted fractures $(n=2)$. The mean length of the calcar segment was $6.4 \pm 4.4 \mathrm{~mm}$. The average medial hinge displacement was $13.4 \pm$ $9.6 \mathrm{~mm}$. The average dual BMD was $-2.5 \pm 0.5$. The mean surgical time was $2.1 \pm 0.8 \mathrm{~h}$. The average intraoperative blood loss was $238 \pm 83 \mathrm{ml}$. Seven cases received anatomical allograft and 15 cases received fibula shaft with LCPs for treatment of PHF (Table 1).

Table 1 Basic information for patients included in this study

\begin{tabular}{|c|c|c|c|c|c|c|c|c|c|c|}
\hline Number & Gender & Age & Involvement & $B M D$ & $\begin{array}{l}\text { Injury } \\
\text { cause }\end{array}$ & $\begin{array}{l}\text { Length of calcar } \\
\text { segment }(\mathrm{mm})\end{array}$ & $\begin{array}{l}\text { Displacement of medial } \\
\text { hinge }(\mathrm{mm})\end{array}$ & $\begin{array}{l}\text { Displacement } \\
\text { direction }\end{array}$ & $\begin{array}{l}\text { Surgical } \\
\text { time }(h)\end{array}$ & $\begin{array}{l}\text { Blood loss } \\
(\mathrm{ml})\end{array}$ \\
\hline 1 & $M$ & 57 & Rt & -2.6 & FSH & 4 & 13 & $\begin{array}{l}\text { Valgus- } \\
\text { impacted }\end{array}$ & 2.1 & 250 \\
\hline 2 & F & 63 & Rt & -2.9 & FSH & 6.6 & 5 & $\begin{array}{l}\text { Valgus- } \\
\text { impacted }\end{array}$ & 1.25 & 200 \\
\hline 3 & F & 59 & $\mathrm{Lt}$ & -2.2 & $F B$ & - & - & Dislocation & 3.2 & 300 \\
\hline 4 & F & 67 & $\mathrm{Lt}$ & -3.2 & FSH & 3 & 12 & - & 1.5 & 100 \\
\hline 5 & M & 66 & $L t$ & -2.8 & FSH & 4 & 15 & - & 2 & 300 \\
\hline 6 & M & 72 & $\mathrm{Rt}$ & -3.1 & FSH & - & - & Dislocation & 3.1 & 500 \\
\hline 7 & $\mathrm{~F}$ & 73 & Rt & -2.1 & FSH & 8 & 7 & - & 2 & 200 \\
\hline 8 & F & 67 & Rt & -2.9 & FSH & 8 & 10 & - & 2 & 300 \\
\hline 9 & $\mathrm{~F}$ & 66 & $L t$ & -3.1 & FSH & - & - & Dislocation & 4 & 300 \\
\hline 10 & M & 62 & Rt & -1.9 & TA & 20 & 20 & - & 3 & 200 \\
\hline 11 & $\mathrm{~F}$ & 77 & $\mathrm{Lt}$ & -2.8 & FSH & 5 & 5 & - & 1.25 & 150 \\
\hline 12 & M & 77 & $\mathrm{Lt}$ & -2.5 & FSH & 8 & 10 & - & 3 & 200 \\
\hline 13 & F & 54 & $\mathrm{Rt}$ & -2.4 & F1M & 8 & 3 & - & 1.75 & 200 \\
\hline 14 & M & 52 & $\mathrm{Lt}$ & -1.9 & FSH & 5 & 16 & - & 1.75 & 150 \\
\hline 15 & $\mathrm{~F}$ & 77 & $\mathrm{Lt}$ & -3.1 & FSH & - & - & Dislocation & 2.75 & 300 \\
\hline 16 & M & 71 & Rt & -2.1 & FSH & 8 & 17 & - & 1.75 & 200 \\
\hline 17 & $\mathrm{~F}$ & 54 & $\mathrm{Lt}$ & -2.3 & F1M & 4 & 14 & - & 1.25 & 200 \\
\hline 18 & M & 84 & $\mathrm{Lt}$ & -2.5 & TA & 12 & 25 & - & 2.5 & 300 \\
\hline 19 & $\mathrm{~F}$ & 79 & $\mathrm{Lt}$ & -2.6 & FSH & 3 & 10 & - & 1.75 & 300 \\
\hline 20 & $\mathrm{~F}$ & 75 & $\mathrm{Lt}$ & -1.6 & FSH & 5 & 16 & - & 1.25 & 200 \\
\hline 21 & $\mathrm{~F}$ & 65 & $L t$ & -2.1 & FSH & 4 & 18 & - & 1.5 & 200 \\
\hline 22 & M & 61 & $\mathrm{Rt}$ & -1.6 & FSH & 4 & 16 & & 1.5 & 200 \\
\hline
\end{tabular}

$M$ male, $F$ female, $R t$ right, $L t$ left, $B M D$ bone mineral density, FSH falling from standing height, $F 1 M$ falling from $1 \mathrm{~m}$ high, $T A$ traffic accident, FB falling from the running bicycle 


\section{Clinical and radiologic outcomes}

The mean follow-up period was 33.4 months (range, 24-48 months). No patient quitted during the whole follow-up period. The rating outcome was "excellent" in 19 cases and "good" in 3 cases (Table 2). The average CMS was 78.2 points (range, 66-90 points), and the mean DASH score was 8.1 points (range, 5.0-13.3).

\section{Functional outcomes}

Functional results at the last follow-up are shown in Table 3. Although there were no significant differences in pain $(P=0.7145)$ and activity $(P=0.6396)$ between the fractured side and the normal side, the range of motion $(\mathrm{ROM})(P<0.05)$ and strength $(P<0.05)$ were considerably limited compared with the normal side.

\section{Comparisons of the clinical outcomes}

Table 4 showed that no significant differences were found in subjective ratings $(P=0.163)$, CMS $(P=0.137)$, and DASH $(P=0.064)$ at the last follow-up between the patients augmented with fibular shaft and anatomical allograft. Also, there were no significant differences in patient subjective ratings $(P=0.727)$, CMS $(P=0.061)$, and DASH $(P=0.059)$ between the patients with shoulder dislocation and without dislocation.

There was no infection or bone nonunion in all of the patients. The mean neck-shaft angle at the last follow-up was $126^{\circ}$ ranging from $90^{\circ}$ to $150^{\circ}$ (data not shown). Among the 15 patients who received fibula shaft, one case developed AVN in the humeral head in combination with screw cutout. After the implant being removed, satisfactory outcomes were achieved (Fig. 3). In

Table 2 Clinical evaluations at the last follow up

\begin{tabular}{|c|c|c|c|c|c|c|c|c|}
\hline Number & Allograft pattern & Follow-up (months) & Neck-shaft angle (degree) & Subjective evaluation & CMS & DASH & Complication & Notification \\
\hline 1 & Fibular shaft & 48 & 125 & Excellent & 86 & 5 & & \\
\hline 2 & Fibular shaft & 28 & 137 & Excellent & 72 & 9.2 & & \\
\hline 3 & Fibular shaft & 30 & 120 & Excellent & 80 & 10.8 & AVN, screw cutout & $\begin{array}{l}\text { Removal of } \\
\text { implant }\end{array}$ \\
\hline 4 & Fibular shaft & 32 & 140 & Excellent & 80 & 6.7 & & \\
\hline 5 & Fibular shaft & 37 & 137 & Excellent & 79 & 6.7 & & \\
\hline 6 & $\begin{array}{l}\text { Anatomical } \\
\text { allograft }\end{array}$ & 42 & 150 & Good & 68 & 7.5 & & \\
\hline 7 & Fibular shaft & 45 & 135 & Excellent & 85 & 5.8 & & \\
\hline 8 & Fibular shaft & 40 & 135 & Excellent & 77 & 10.8 & & \\
\hline 9 & Fibular shaft & 39 & 120 & Excellent & 79 & 6.7 & & \\
\hline 10 & Fibular shaft & 35 & 135 & Good & 76 & 5.8 & & \\
\hline 11 & Fibular shaft & 25 & 120 & Excellent & 82 & 7.5 & & \\
\hline 12 & Fibular shaft & 27 & 140 & Excellent & 72 & 10 & & \\
\hline 13 & Fibular shaft & 30 & 135 & Excellent & 82 & 9.2 & & \\
\hline 14 & Fibular shaft & 38 & 90 & Excellent & 76 & 5.8 & $\begin{array}{l}\text { Varus displacement of } \\
\text { humeral head }\end{array}$ & Observation \\
\hline 15 & $\begin{array}{l}\text { Anatomical } \\
\text { allograft }\end{array}$ & 31 & 120 & Excellent & 66 & 13.3 & & \\
\hline 16 & $\begin{array}{l}\text { Anatomical } \\
\text { allograft }\end{array}$ & 30 & 124 & Excellent & 79 & 9.2 & & \\
\hline 17 & $\begin{array}{l}\text { Anatomical } \\
\text { allograft }\end{array}$ & 36 & 134 & Excellent & 74 & 9.2 & & \\
\hline 18 & $\begin{array}{l}\text { Anatomical } \\
\text { allograft }\end{array}$ & 24 & 110 & Good & 82 & 10 & & \\
\hline 19 & $\begin{array}{l}\text { Anatomical } \\
\text { allograft }\end{array}$ & 27 & 120 & Excellent & 74 & 6.7 & & \\
\hline 20 & $\begin{array}{l}\text { Anatomical } \\
\text { allograft }\end{array}$ & 26 & 120 & Excellent & 85 & 9.2 & & \\
\hline 21 & Fibular shaft & 28 & 120 & Excellent & 90 & 5.8 & & \\
\hline 22 & Fibular shaft & 36 & 110 & Excellent & 76 & 6.7 & & \\
\hline
\end{tabular}

CMS Constant-Murley score, DASH the disability of the arm, shoulder and hand, AVN avascular necrosis 
Table 3 Functional results at the last follow-up according to the CMS

\begin{tabular}{|c|c|c|c|}
\hline Variable & $\begin{array}{l}\text { Fractured side } \\
(n=22)\end{array}$ & $\begin{array}{l}\text { Normal side } \\
(n=22)\end{array}$ & $P$ value \\
\hline Pain (0-15) & $13.6 \pm 2.8$ & $13.9 \pm 2.6$ & 0.7145 \\
\hline Activity (0-20) & $9.1 \pm 1.9$ & $8.8 \pm 2.3$ & 0.6396 \\
\hline \multicolumn{4}{|l|}{$\mathrm{ROM}(0-40)$} \\
\hline Abduction & $6.7 \pm 1.5$ & $9.3 \pm 1.2^{*}$ & 0.0000 \\
\hline Anterior elevation & $7.4 \pm 1.3$ & $8.9 \pm 1.2^{*}$ & 0.0003 \\
\hline $\begin{array}{l}\text { External rotation with } \\
\text { elbow at the side }\end{array}$ & $7.5 \pm 1.5$ & $9.7 \pm 0.7^{*}$ & 0.0000 \\
\hline $\begin{array}{l}\text { Internal rotation in } \\
\text { abduction }\end{array}$ & $7.7 \pm 1.0$ & $8.9 \pm 0.9^{*}$ & 0.0001 \\
\hline Strength $(0-25)$ & $16.5 \pm 3.4$ & $23.9 \pm 2.0^{*}$ & 0.0000 \\
\hline
\end{tabular}

CMS Constant-Murley score, $R O M$ range of motion

${ }^{*} P<0.01$

addition, one patient encountered varus displacement, but the patient acquired good function without the need of revision (Fig. 4).

\section{Discussion}

PHF has been ranked as the third frequent fractures among elderly patients, followed by hip fractures and distal radius fractures [17], and has a strong correlation with osteoporosis [18]. Most of PHFs can be managed nonoperatively but with decreased shoulder fusion [19]. The four-part PHF represents about $3 \%$ of all PHFs and is regarded as one of the most difficult PHFs to deal with [3]. In our series, we investigated the clinical outcomes of anatomical allograft or fibula shaft in treatment of LCPs in old people four-part PHF. The results showed that the efficacies of fibular shaft and anatomical allograft surgery strategies were similar, and both of them produced relatively satisfactory anatomical and functional outcomes.

The reconstruction of medial stability of the proximal humeral fracture sites seemed to promote fracture healing or revascularization of the humeral head, especially for patients with glenohumeral dislocation or medial comminution. In 1996, Walch et al. [20] firstly reported intramedullary strut grafting for treatment of the humerus neck nonunion. Peng et al. [21] found that adjuvant use of intramedullary strut allograft could significantly enhance bone union in elderly patients with three- and/or four-part fractures. Russo et al. [22] used triangular allogeneic grafts in 33 patients with sustained three- or four-part fractures; apart from one patient who encountered AVN, all fractures healed successfully. Lorich et al. [23] employed an endosteal cortical allograft strut in 38 patients with displaced PHF and found that this new technique reduced complications related to LCPs and improved clinical outcomes. Similarly, in our series, anatomical allograft or fibula shaft with LCPs was performed in elderly patients with four-part PHF. The results indicated that there were no significant differences in patient subjective ratings and CMS and DASH scores between the patients augmented with fibular shaft and anatomical allograft. Interestingly, the ROM and strength were considerably limited compared with the normal side in our study, which might be different from other studies. The possible reasons may be that the participants in our study were all elderly patients whose rehabilitation ability was limited. However, there were no significant differences in pain and daily activity between the unaffected and affected sides at the last follow-up according to the CMS. Although one case developed AVN and screw cutout, and another case developed varus displacement, both of them acquired good function at the last follow-up. Moreover, there were no infection, bone nonunion, and hardwarerelated complications in any case. All the above results suggested that medial stability could promote revascularization of the humeral head and allow bone fracture healing.

The similarly good clinical outcomes in our study might be related with some factors. Fibular allograft used as volumetric filling in the bone void formed after reduction of humeral neck-shaft angle could push the humeral head resistance to the force from the scapular fossa along with the screws, preventing the screw penetrating into the articular surface. Besides, this medial strut could prevent the varus placement of the head to diminish humeral head varus collapse and reduce the incidence of malunion. Anatomical medial strut with allograft bone has more potential to prevent humeral head varus displacement compared with the isolated fibula allograft. Anatomical allograft should be modified into a specific shape to fill the bone void according to the intramedullary geometry of the proximal humerus through computer

Table 4 Comparison among clinical outcomes

\begin{tabular}{|c|c|c|c|c|c|c|c|c|c|c|}
\hline & & Excellent & Good & Fair & Poor & $P$ value & CMS & $P$ value & DASH & $P$ value \\
\hline \multirow[t]{2}{*}{ Pattern } & Fibular shaft (15) & 14 & 1 & - & - & 0.163 & $79.47 \pm 5.012$ & 0.137 & $7.5 \pm 1.967$ & 0.064 \\
\hline & Anatomical allograft (7) & 5 & 2 & - & - & & $75.43 \pm 7.020$ & & $9.3 \pm 2.102$ & \\
\hline \multirow[t]{2}{*}{ Displacement } & Dislocation (4) & 3 & 1 & - & - & 0.727 & $73.25 \pm 7.27$ & 0.061 & $9.6 \pm 3.052$ & 0.059 \\
\hline & No dislocation (18) & 16 & 2 & - & - & & $79.28 \pm 5.13$ & & $7.74 \pm 1.83$ & \\
\hline
\end{tabular}

CMS Constant-Murley score, DASH the disability of the arm, shoulder and hand 

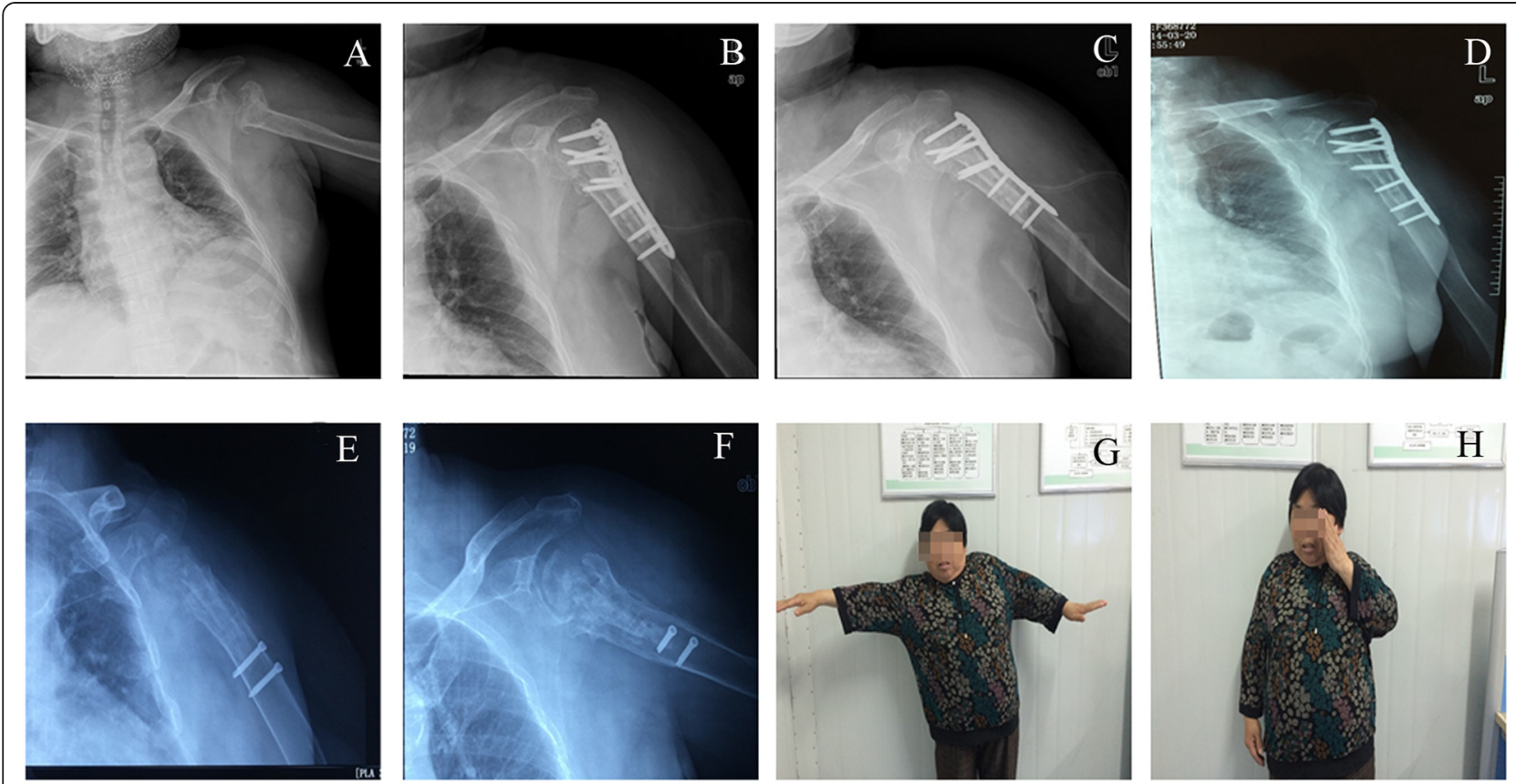

Fig. 3 One case develops AVN and screw cutout but gets satisfactory outcomes after the implant is being removed. a X-ray film before surgery. b X-ray film after surgery. $\mathbf{c}$ X-ray film 3 months after surgery. $\mathbf{d}$ X-ray film 12 months after surgery. e, $\mathbf{f}$ X-ray film 30 months after surgery. $\mathbf{g}$, $\mathbf{h}$ Function of patient's upper arm
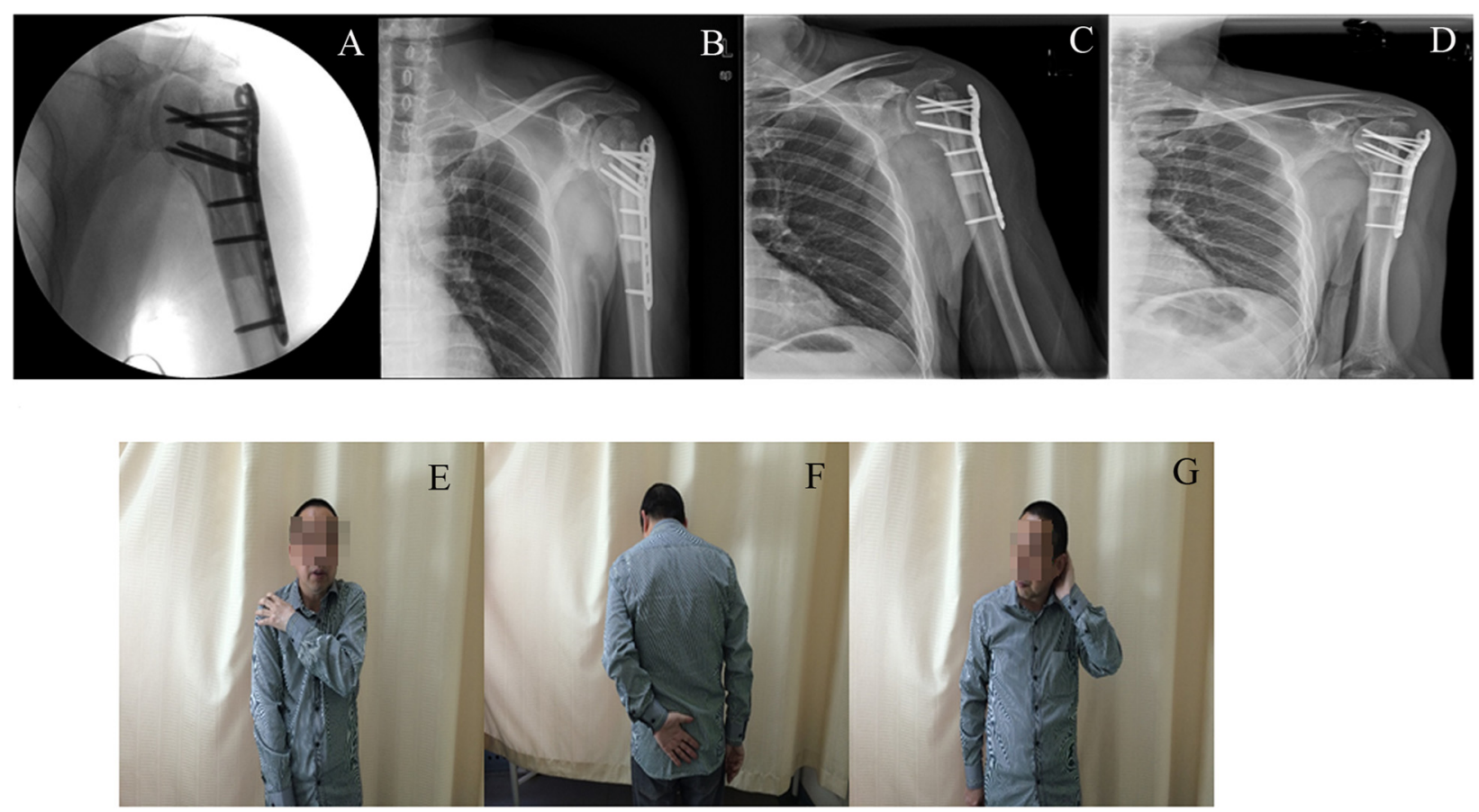

Fig. 4 One case develops varus displacement but acquires good function without need of revision. a X-ray film before surgery. $\mathbf{b}$ X-ray film 3 days after surgery. c X-ray film 3 months after surgery. d X-ray film 38 months after surgery. e-g Function of patient's upper arm 
virtual design with Pro-E software. This kind of structural allograft provides enough medial stability and allows the formation of osteogenic tissue across a fracture site along with the surface of the allograft followed by bone formation. In addition, faster fracture healing could minimize articular segment AVN or collapse. Anatomical allograft is a plane contacted with the humeral head, and the support position could be pushed to the inferior medial point. However, isolated fibula was just a point-to-point support of the humeral head, and the support point is just at the line of extension of the intramedullary canal direction.

\section{Conclusions}

In conclusion, fibular shaft or anatomical allograft with LCPs produces similarly functional results and satisfactory results. The implantation promotes fracture healing without interfering blood supply to the humeral head.

\section{Competing interests}

The authors declare that they have no competing interests.

\section{Authors' contributions}

$\mathrm{HC}$ and XRJ participated in the design of this study, and they both performed the statistical analysis. QZ and XDL carried out the study and collected important background information. PFT drafted the manuscript. All authors read and approved the final manuscript.

Received: 11 March 2015 Accepted: 5 July 2015

Published online: 22 July 2015

\section{References}

1. Baron JA, Karagas M, Barrett J, Kniffin W, Malenka D, Mayor M, et al. Basic epidemiology of fractures of the upper and lower limb among Americans over 65 years of age. Epidemiology. 1996;7(6):612-8.

2. Vachtsevanos $L$, Hayden $L$, Desai AS, Dramis A. Management of proximal humerus fractures in adults. World J Orthoped. 2014;5(5):685.

3. Court-Brown CM, Garg A, McQueen MM. The epidemiology of proximal humeral fractures. Acta orthopaedica Scandinavica. 2001;72(4):365-71. doi:10.1080/000164701753542023.

4. Burkhart KJ, Dietz SO, Bastian L, Thelen U, Hoffmann R, Muller LP. The treatment of proximal humeral fracture in adults. Deutsches Arzteblatt international. 2013;110(35-36):591-7. doi:10.3238/arztebl.2013.0591.

5. Gaebler C, McQueen M, Court-Brown C. Minimally displaced proximal humeral fractures: epidemiology and outcome in 507 cases. Acta Orthopaedica. 2003;74(5):580-5.

6. Naranja RJ, lannotti JP. Displaced three- and four-part proximal humerus fractures: evaluation and management. J Am Acad Orthop Surg. 2000;8(6):373-82.

7. Yüksel HY, Yimaz S, Aksahin E, Çelebi L, Muratli HH, Biçimoglu A. The results of nonoperative treatment for three-and four-part fractures of the proximal humerus in low-demand patients. J Orthop Trauma. 2011;25(10):588-95.

8. lyengar JJ, Devcic Z, Sproul RC, Feeley BT. Nonoperative treatment of proximal humerus fractures: a systematic review. J Orthop Trauma. 2011;25(10):612-7.

9. Phipatanakul W, Norris T. Indications for prosthetic replacement in proximal humeral fractures. Instr Course Lect. 2004;54:357-62.

10. Aaron D, Parsons B, Sirveaux F, Flatow E. Proximal humeral fractures: prosthetic replacement. Instr Course Lect. 2012;62:155-62.

11. Kontakis G, Koutras C, Tosounidis T, Giannoudis P. Early management of proximal humeral fractures with hemiarthroplasty: a systematic review. J Bone Joint Surg. 2008;90(11):1407-13.

12. Clavert P, Adam P, Bevort A, Bonnomet F, Kempf J-F. Pitfalls and complications with locking plate for proximal humerus fracture. J Shoulder Elbow Surg. 2010;19(4):489-94.
13. Ricchetti ET, Warrender WJ, Abboud JA. Use of locking plates in the treatment of proximal humerus fractures. J Shoulder Elbow Surg. 2010;19(2 Suppl):66-75. doi:10.1016/j.jse.2010.01.001.

14. Kim SH, Lee YH, Chung SW, Shin SH, Jang WY, Gong HS, et al. Outcomes for four-part proximal humerus fractures treated with a locking compression plate and an autologous iliac bone impaction graft. Injury. 2012;43(10):1724-31. doi:10.1016/j.injury.2012.06.029.

15. Singer $G$, Ferlic $P$, Kraus $T$, Eberl R. Reconstruction of the sternoclavicular joint in active patients with the figure-of-eight technique using hamstrings. J Shoulder Elbow Surg. 2013;22(1):64-9.

16. Pingsmann A, Patsalis T, Michiels I. Resection arthroplasty of the sternoclavicular joint for the treatment of primary degenerative sternoclavicular arthritis. J Bone Joint Surg. 2002;84(4):513-7.

17. Barrett JA, Baron JA, Karagas MR, Beach ML. Fracture risk in the US Medicare population. J Clin Epidemiol. 1999;52(3):243-9.

18. Cai M, Tao K, Yang C, Li S. Internal fixation versus shoulder hemiarthroplasty for displaced 4-part proximal humeral fractures in elderly patients. Orthopedics. 2012;35(9):748.

19. Edelson G, Safuri H, Salami J, Vigder F, Militianu D. Natural history of complex fractures of the proximal humerus using a three-dimensional classification system. J Shoulder Elbow Surg. 2008;17(3):399-409. doi:10.1016/j.jse.2007.08.014.

20. Walch G, Badet R, Nove-Josserand L, Levigne C. Nonunions of the surgical neck of the humerus: surgical treatment with an intramedullary bone peg, internal fixation, and cancellous bone grafting. J Shoulder Elbow Surg. 1996;5(3):161-8.

21. Peng C-H, Wu W-T, Yu T-C, Chen L-C, Hsu S-H, Kwong S-T, et al. Surgical treatment for proximal humeral fracture in elderly patients with emphasis on the use of intramedullary strut allografts. Tzu Chi Medical Journal. 2012;24(3):131-5.

22. Russo R, Visconti V, Lombardi LV, Ciccarelli M, Giudice G. The block-bridge system: a new concept and surgical technique to reconstruct articular surfaces and tuberosities in complex proximal humeral fractures. J Shoulder Elbow Surg. 2008;17(1):29-36. doi:10.1016/j.jse.2007.03.027.

23. Neviaser AS, Hettrich CM, Beamer BS, Dines JS, Lorich DG. Endosteal strut augment reduces complications associated with proximal humeral locking plates. Clin Orthop Relat Res. 2011;469(12):3300-6. doi:10.1007/ s11999-011-1949-0.

\section{Submit your next manuscript to BioMed Central and take full advantage of:}

- Convenient online submission

- Thorough peer review

- No space constraints or color figure charges

- Immediate publication on acceptance

- Inclusion in PubMed, CAS, Scopus and Google Scholar

- Research which is freely available for redistribution 